Jurnal Kesehatan Masyarakat

\title{
PENDIDIKAN SEKSUAL DAN PERILAKU PEMENUHAN KEBUTUHAN SEKSUAL PASANGAN MASA KEHAMILAN
}

\author{
Yuni Purwati ${ }^{1 凶}$, Irwan Taufiqur Rachman ${ }^{2}$, Akhmadi $^{3}$ \\ ${ }^{1}$ Sekolah Tinggi Ilmu Kesehatan Aisyiyah Yogyakarta \\ ${ }^{2}$ RSUP Dr. Sardjito Yogyakarta \\ ${ }^{3}$ Fakultas Kedokteran Universitas Gadjah Mada Yogyakarta
}

\section{Info Artikel}

Sejarah Artikel:

Diterima 14 November 2014

Disetujui 28 November 2014

Dipublikasikan Januari 2015

Keywords:

Sexual education;

Sexual behavior;

Pregnancy.

\begin{abstract}
Abstrak
Sebanyak 30-50\% pasangan khawatir hubungan seksual akan membahayakan janinnya. Tujuan penelitian ini untuk mengetahui pengaruh pendidikan seksual terhadap perilaku pemenuhan kebutuhan seksual pasangan masa kehamilan di Puskesmas Kasihan II Bantul. Penelitian menggunakan rancangan quasi-eksperimental metode non-equivalent control group design. Sampel terdiri 26 subyek kelompok eksperimen dan 26 subyek kelompok kontrol, dengan metode purposive sampling. Instrumen berupa kuesioner yang telah diuji validitas korelasi product moment dan uji reliabilitas alpha cronbach. Analisis data menggunakan paired samples $t$-test dan independent samples t-test. Hasil uji normalitas data menggunakan kolmogorov-sminorv $\mathrm{p}>\alpha=0,05$, sehingga data terdistribusi normal. Hasil analisis paired $t$-test kelompok eksperimen adalah $\mathrm{p}<0,05$, hasil kelompok kontrol $\mathrm{p}>0,05$ dan hasil independent samples $t$-test kelompok eksperimen dan kelompok kontrol yaitu $\mathrm{p}<0,05$. Disimpulkan terdapat pengaruh signifikan pemberian pendidikan seksual terhadap perilaku pemenuhan kebutuhan seksual masa kehamilan di Puskesmas Kasihan II Bantul.
\end{abstract}

\section{Sexual Education and Sexual Behavior in Couples During Pregnancy}

\begin{abstract}
Both physical and psychological changes during pregnancy could influence sexuality 30$50 \%$ of couples concerned that intercourse will injure the fetus. The purpose of the study was to determine the effect of sexuality education on sexual behavior among couples during pregnancy at Puskesmas Kasihan II Bantul Yogyakarta. The quasi-experimental method with a non-equivalent control group was used in this study. The sample consisted of 26 subjects as an experimental group and as control of 26 subjects group with sampling technique using purposive sampling. Data collection instrument was a questionnaire that tested the validity of using the product moment correlation and cronbach alpha reliability test. Pretest and posttest control group performed at the same time as the experimental group. Statistical analysis of paired $t$-test and independent samples $t$-test. There was no significant differences in background characteristic between intervention and control group. Results of statistical analysis of paired t-tests on the sexual behavior experimental group $p<0.05$, resulting in the control group $p>0.05$. The results of independent samples $t$-test in the experimental group and the control group $p<0.05$. Conclusions there was significant difference sexuality education using group discussions on sexual behavior among couples during pregnancy at Puskesmas Kasihan II Bantul Yogyakarta.
\end{abstract}

(c) 2015 Universitas Negeri Semarang 


\section{Pendahuluan}

Kehamilan merupakan salah satu peristiwa penting dalam kehidupan perempuan. Kehamilan menuntut respon adaptif dari ibu hamil dan orang terdekatnya (Araujo, 2012).

Perubahan fisik dan psikologis masa kehamilan dapat mempengaruhi ikatan afektif dengan suami. Menurut Uwapusitanon (2004) dan Araujo, (2012), pada trimester pertama gairah seksual ibu hamil umumnya menurun karena morning sickness dan kelelahan yang mempengaruhi semangat, hasrat dan libido. Memasuki trimester kedua, libido membaik karena tubuh telah dapat beradaptasi dengan kehamilan dan dapat menikmati aktifitas seksual dengan lebih nyaman. Pada trimester ketiga libido dapat menurun kembali, ketidaknyaman karena semakin besarnya abdomen, rasa nyeri punggung dan ketakutan menghadapi persalinan.

Berdasarkan epidemiologi masalah seksual masa kehamilan, 30-50\% pasangan takut aktivitas seksual akan membahayakan janinnya. Suami takut menyakiti istri dan istri khawatir tidak dapat memuaskan suami (Brtnicka, 2009). Ibu hamil menganggap selama kehamilan penting untuk menghindari hubungan seksual dan kehamilan merupakan masa bebas dari hubungan seksual. Ibu hamil merasa tidak percaya diri, tidak menarik dan tidak diinginkan suami. Kehamilan dirasakan sebagai beban berat sehingga dapat mengalami gangguan hubungan seksual

Penurunan pemenuhan kebutuhan seksual dapat berkontribusi pada kecemasan yang dapat mengganggu status kesehatan ibu dan janinnya. Berkurangnya aktivitas seksual dapat menjadi penyebab suami mencari hubungan seksual tidak aman. Seksualitas yang bermasalah dapat menjadi faktor penyebab retaknya hubungan perkawinan. Terdapat 4-28\% suami berselingkuh selama kehamilan istri dan meningkatkan risiko penyakit menular seksual seperti infeksi HIV yang berdampak buruk bagi status kesehatan ibu hamil dan janinnya (Brtnicka, 2009).

Pasangan dengan ibu hamil perlu mengenali masalah seksual pada masa kehamilan dan menentukan jalan keluar untuk mengatasinya. Pendidikan seksualitas dengan metode diskusi kelompok merupakan metode yang tepat sebagai upaya promosi kesehatan. Metode diskusi kelompok merupakan saluran yang baik untuk menjaga kredibilitas pesan-pesan, menyediakan informasi, dan mengajarkan ketrampilan kompleks yang membutuhkan komunikasi dua arah. Diskusi kelompok dapat memicu saling keterbukaan dalam membicarakan pengalaman seksualitasnya (Kumboyono, 2009).

Hasil studi pendahuluan terhadap tiga pasangan dengan ibu hamil di Puskesmas Kasihan II Bantul, satu subyek menyatakan melakukan hubungan seksual apabila suami menginginkan. Subyek kedua dan ketiga menya- takan tidak mau melakukan hubungan seksual pada masa kehamilan supaya tidak menciderai janinnya. Tujuan penelitian dapat diketahui pengaruh pendidikan seksual melalui diskusi kelompok terhadap perilaku pemenuhan kebutuhan seksual pasangan masa kehamilan di Puskesmas Kasihan II Bantul.

\section{Metode}

Penelitian dilakukan pada tahun 2013 ang dilakukan pada wilayah kerja Puskesmas Kasihan II, Bantul. Rancangan penelitian dengan quasi-eksperimental metode nonequivalent control group design. Pengambilan sampel dengan purposive sampling, terdiri 52 pasang responden, 26 pasang kelompok eksperimen dan 26 pasang kelompok kontrol. Kriteria inklusi adalah ibu hamil primigravida trimester satu dan dua, berusia 20-35 tahun, tinggal di Kecamatan Kasihan Bantul, suami istri pendidikan minimal SD. Kriteria eksklusi tidak tinggal serumah dengan pasangan, kehamilan berisiko (riwayat perdarahan, abortus, hiperemesis gravidarum).

Instrumen pengumpulan data berupa kuesioner terdiri domain pengetahuan 20 item, sikap 20 item dan praktek 14 item pertanyaan yang disusun peneliti berdasarkan studi referensi pustaka dan hasil penelitian. Uji validitas instrumen menggunakan korelasi product moment dengan nilai signifikansi $<\alpha=0,05$. Uji reliabilitas dengan koefisien reliabilitas alpha cronbach, hasilnya $>0,07$, sehingga dinyatakan valid dan reliabel.

Penelitian kelompok eksperimen dilakukan di Puskesmas Induk dan kelompok kontrol 
di Puskesmas Pembantu Kasihan II Bantul. Pada kelompok eksperimen pre test dilakukan sebelum pendidikan seksual. Post test domain pengetahuan dan sikap dilaksanakan 1 minggu setelah pendidikan seksual dan domain praktek 3 minggu setelah pendidikan seksual. Pada kelompok kontrol tanpa diberikan pendidikan seksual, pengambilan data pre test dan post test dilakukan pada waktu yang sama dengan kelompok intervensi. Setelah pengambilan data post test domain praktek pada kelompok kon- trol, selanjutnya diberikan booklet dan pendidikan seksual pada setiap pasangan dilakukan di rumah responden. Analisis data menggunakan paired samples t-test dan independent samples t-test.

\section{Hasil dan Pembahasan}

Hasil penelitian mencakup karakteristik dan uji homogenitas responden, data penelitian perilaku pemenuhan kebutuhan seksual yang

Tabel 1. Distribusi Frekuensi dan Uji Homogenitas Responden

\begin{tabular}{|c|c|c|c|c|c|c|}
\hline \multirow{2}{*}{ No } & \multirow{2}{*}{ Karakteristik } & \multicolumn{2}{|c|}{ Intervensi } & \multicolumn{2}{|c|}{ Kontrol } & \multirow{2}{*}{ P value } \\
\hline & & $\mathrm{f}$ & $\%$ & $\mathrm{f}$ & $\%$ & \\
\hline \multirow[t]{3}{*}{1} & Usia Istri (tahun) & & & & & 1,000 \\
\hline & 20-30 tahun & 20 & 76,9 & 20 & 76,9 & \\
\hline & $>30-35$ tahun & 6 & 23., & 6 & 23,1 & \\
\hline \multirow[t]{3}{*}{2} & Pendidikan Istri & & & & & 0,149 \\
\hline & Pendidikan Dasar & 9 & 34,6 & 12 & 46,2 & \\
\hline & Pendidikan Tinggi & 17 & 65,4 & 14 & 53,8 & \\
\hline \multirow[t]{3}{*}{3} & Pendidikan Suami & & & & & 0,565 \\
\hline & Pendidikan Dasar & 8 & 30,8 & 9 & 34,6 & \\
\hline & Pendidikan tinggi & 18 & 69,2 & 17 & 65,4 & \\
\hline \multirow[t]{3}{*}{4} & Trimester Kehamilan & & & & & 0,061 \\
\hline & Trimester Pertama & 21 & 80,8 & 18 & 69,2 & \\
\hline & Trimester Kedua & 5 & 19,2 & 8 & 30,8 & \\
\hline \multirow[t]{2}{*}{5} & Lama pernikahan & & & & & 0,473 \\
\hline & $\begin{array}{l}\leq 12 \text { bulan } \\
>12 \text { bulan }\end{array}$ & $\begin{array}{c}21 \\
5\end{array}$ & $\begin{array}{l}80,76 \\
19,23\end{array}$ & $\begin{array}{c}22 \\
4\end{array}$ & $\begin{array}{l}88,46 \\
15,38\end{array}$ & \\
\hline
\end{tabular}

Sumber : data primer

Tabel 2.Distribusi Frekuensi Perilaku Pemenuhan Kebutuhan Seksual

\begin{tabular}{|c|c|c|c|c|c|c|c|c|c|}
\hline \multirow{3}{*}{ No } & \multirow{3}{*}{ Domain Perilaku } & \multicolumn{4}{|c|}{ Kelompok Eksperimen } & \multicolumn{4}{|c|}{ Kelompok Kontrol } \\
\hline & & \multicolumn{2}{|c|}{ Pre Test } & \multicolumn{2}{|c|}{ Post Test } & \multicolumn{2}{|c|}{ Pre Test } & \multicolumn{2}{|c|}{ Post Test } \\
\hline & & $\mathrm{f}$ & $\%$ & $\mathrm{f}$ & $\%$ & $\mathrm{f}$ & $\%$ & $\mathrm{f}$ & $\%$ \\
\hline \multirow[t]{4}{*}{1} & Pengetahuan & & & & & & & & \\
\hline & Kurang baik & 5 & 19,2 & 0,0 & 0,0 & 1 & 3,8 & 2 & 7,7 \\
\hline & Cukup baik & 18 & 69,2 & 1 & 3,8 & 23 & 88,5 & 19 & 73,1 \\
\hline & Baik & 3 & 11,5 & 25 & 96,2 & 2 & 7,7 & 5 & 19,2 \\
\hline \multirow[t]{4}{*}{2} & Sikap & & & & & & & & \\
\hline & Kurang baik & 0,0 & 0,0 & 0,0 & $0,0,0$ & 3 & 11,5 & 3 & 11,5 \\
\hline & Cukup baik & 24 & 92,3 & 10 & 38,5 & 23 & 88,5 & 23 & 88,5 \\
\hline & Baik & 2 & 7,7 & 16 & 61,5 & 0,0 & 0,0 & 0,0 & 0,0 \\
\hline \multirow[t]{4}{*}{3} & Praktek & & & & & & & & \\
\hline & Kurang baik & 0,0 & 0,0 & 0,0 & 0,0 & 5 & 19,2 & 7 & 26,9 \\
\hline & Cukup baik & 24 & 92,3 & 5 & 19,2 & 16 & 61,5 & 13 & 50,0 \\
\hline & Baik & 2 & 7,7 & 21 & 80,8 & 5 & 19,2 & 6 & 23,1 \\
\hline
\end{tabular}

Sumber : data primer 
Tabel 3. Hasil Uji Normalitas Data Perilaku Pemenuhan Kebutuhan Seksual

\begin{tabular}{llccl}
\hline Kelompok & \multicolumn{1}{c}{ Domain } & Nilai $\alpha$ & $\begin{array}{c}\text { Asymp.Sig. } \\
\text { (2-tailed) }\end{array}$ & \multicolumn{1}{c}{ Hasil } \\
\hline Eksperimen & Pengetahuan (pretest) & 0,05 & 0,291 & Normal \\
& Pengetahuan (postest) & 0,05 & 0,231 & Normal \\
& Sikap (pretest) & 0,05 & 0,461 & Normal \\
& Sikap (posttest) & 0,05 & 0,693 & Normal \\
& Praktek (posttest) & 0,05 & 0,149 & Normal \\
& Praktek (posttest) & 0,05 & 0,482 & Normal \\
\hline \multirow{2}{*}{ Kontrol } & Pengetahuan (pretest) & 0,05 & 0,659 & Normal \\
& Pengetahuan (postest) & 0,05 & 0,703 & Normal \\
& Sikap (pretest) & 0,05 & 0,935 & Normal \\
& Sikap (posttest) & 0,05 & 0,350 & Normal \\
& Praktek (posttest) & 0,05 & 0,721 & Normal \\
& Praktek (posttest) & 0,05 & 0,764 & Normal \\
\hline
\end{tabular}

Sumber : data primer

terdiri dari domain pengetahuan, sikap, dan pertama 18 responden $(69,2 \%)$, dan lama pernipraktek. kahan $<12$ bulan 22 responden $(88,46 \%)$. Data

Responden kelompok eksperimen kelompok eksperimen dan kelompok kontrol paling banyak berusia 20-30 tahun, yaitu 20 dinyatakan homogen dengan nilai $p>\alpha=0,05$. responden (76,\%), pendidikan istri tinggi 17 Pada kelompok eksperimen, sebelum responden $(65,6 \%)$, pendidikan suami tinggi pendidikan seksualitas hasil paling banyak pada 18 responden $(69,2 \%)$ dan merupakan kehami- domain pengetahuan adalah kategori cukup lan trimester pertama 21 responden $(80,8 \%)$ baik 18 responden $(69,2 \%)$, sikap cukup baik 24 dan lama pernikahan $<12$ bulan 21 responden responden (92,3\%), dan praktek cukup baik 24 $(80,76 \%)$. Responden kelompok kontrol paling responden (92,3\%). Hasil paling banyak setelah banyak berusia 20-30 tahun, yaitu 20 responden pendidikan seksualitas pada domain pengeta(76,\%), pendidikan istri tinggi 14 responden huan kategori baik 25 responden (96,2\%), sikap $(53,8 \%)$, pendidikan suami tinggi 17 responden baik 16 responden (61,5\%), dan praktek baik 21 $(65,4 \%)$, dan merupakan kehamilan trimester responden $(80,8 \%)$.

Tabel 4. Paired Samples T-Test Perilaku Pemenuhan Kebutuhan Seksual

\begin{tabular}{|c|c|c|c|c|c|c|c|}
\hline \multirow{2}{*}{\multicolumn{2}{|c|}{ Hasil Analisis }} & \multicolumn{3}{|c|}{ Paired samples $t$-test kelompok eksperimen } & \multicolumn{3}{|c|}{ Paired samples t-test kelompok kontrol } \\
\hline & & Pengetahuan & Sikap & Praktek & Pengetahuan & Sikap & Praktek \\
\hline \multicolumn{2}{|l|}{ Mean } & -1.038 & -0.462 & -0.731 & -0.077 & - & -0.038 \\
\hline \multicolumn{2}{|l|}{$\mathrm{t}$} & -10.024 & -4.045 & -8.238 & -0.811 & - & -0.440 \\
\hline \multicolumn{2}{|l|}{ Sig. } & 0.000 & 0.000 & 0.000 & 0.425 & - & 0.554 \\
\hline $95 \%$ & Lower & -1.252 & -0.697 & -0.227 & -2.272 & - & -0.218 \\
\hline $\mathrm{CI}$ & Upper & -0.825 & -0.913 & -0.548 & 0.118 & - & 0.141 \\
\hline
\end{tabular}

Sumber : data primer

Tabel 5. Independent Samples Test Perilaku Pemenuhan Kebutuhan Seksual

\begin{tabular}{lccccc}
\hline \multirow{2}{*}{ Domain } & \multirow{2}{*}{$\mathrm{t}$} & Sig. $(2$ tailed $)$ & \multirow{2}{*}{$\begin{array}{c}\text { Mean } \\
\text { Difference }\end{array}$} & Lower & Upper \\
\hline Pengetahuan & 7.008 & 0.000 & 3.923 & 2.787 & 5.059 \\
Sikap & 7.215 & 0.000 & 9.423 & 6.765 & 12.081 \\
Praktek & 7.458 & 0.000 & 6.515 & 4.815 & 8.416 \\
\hline
\end{tabular}

Sumber : data primer 
Pada pre test dan post test kelompok kontrol, hasil paling banyak kategori cukup baik 23 responden $(88,5 \%)$ dan 19 responden $(73,1 \%)$, sikap, cukup baik, pre test dan post test sama, 23 responden $(88,5 \%)$. Pada domain praktek paling banyak cukup baik 16 responden (61,5\%) dan 13 responden (50\%).

Hasil uji normalitas data menunjukkan $p>\alpha=0,05$, sehingga data terdistribusi normal. Analisis statistik yang dapat digunakan yaitu uji parametris paired t-test dan independent samples $t$-t-test.

Hasil uji paired samples test kelompok eksperimen pada domain perilaku yaitu pengetahuan, sikap dan praktek, menunjukkan sig. (2-tailed) 0,0001 $<\alpha=0,05$. Hasil $t$ hitung $>t$ tabel $=1,708$, sehingga pemberian pendidikan seksual masa kehamilan terbukti dapat meningkatkan perilaku (pengetahuan, sikap, dan praktek) pemenuhan kebutuhan seksual pada pasangan dengan masa kehamilan di Puskesmas Kasihan II Bantul.

Hasil paired samples t-test kelompok kontrol menunjukkan $p>\alpha=0,05$. Hasil ini membuktikan tidak ada perbedaan perilaku antara pre test dan post test kelompok yang tidak mendapat pendidikan seksual.

Hasil analisis independent samples t-test perilaku domain pengetahuan, sikap dan praktek menunjukkan nilai $\mathrm{p}<\alpha=0,05$, hasil t hitung $>\mathrm{t}$ tabel $=2,0634$. Kesimpulannya terdapat pengaruh yang signifikan pemberian pendidikan seksual melalui diskusi kelompok terhadap perilaku pemenuhan kebutuhan seksual pasangan masa kehamilan. Perilaku (pengetahuan, sikap dan praktek) pemenuhan kebutuhan seksual pada pasangan masa kehamilan di Puskesmas Kasihan II Bantul kelompok intervensi secara signifikan lebih baik dibandingkan dengan kelompok kontrol.

Hasil paired samples t-test pada domain pengetahuan kelompok intervensi setelah diberikan pendidikan seksual secara signifikan lebih baik daripada sebelum diberikan pendidikan seksual, nilai $\mathrm{p}<\alpha=0,05$. Peningkatan pengetahuan ini terjadi sebagai akibat proses belajar yang diberikan melalui pendidikan seksual. Proses belajar melalui pendidikan akan terjadi proses perubahan ke arah yang lebih baik dan lebih matang pada individu. Pasangan ibu hamil yang tidak tahu menjadi lebih tahu, yang tidak mampu menjadi lebih mampu mengatasi masalah kesehatannya sendiri.

Hasil ini sejalan dengan penelitian Najimi (2013), yang menyatakan peningkatan pengetahuan yang signifikan $(\mathrm{p}<0,001)$, setelah pendidikan kesehatan kepada ibu tentang pencegahan kejang demam pada anak-anak. Pemberian intervensi pendidikan dapat mening katkan rasa percaya diri dan ketenangan batin ibu. Pengetahuan yang benar dapat mengurangi kekhawatiran dan ketakutan akibat hubungan seksual masa kehamilan yang diyakini dapat menciderai janin maupun mengakibatkan kega galan kehamilan. Pasangan dengan ibu hamil dapat lebih mengetahui tentang perubahan seksual pada setiap trimester kehamilan, meluruskan mitos dan mengetahui ibu hamil yang dilarang melakukan hubungan seksual pada masa kehamilan. Pasangan dengan ibu hamil dapat mengetahui posisi dan frekuensi hubung an seksual yang aman, mengkomunikasikan kebutuhan seksual serta mempertahankan hubungan non seksual masa kehamilan.

Pemilihan metode diskusi kelompok dapat memicu peserta saling bertanya, bertukar pendapat dan mengomentari pengalaman serta pandangan peserta lain. Menurut Frith (2004), metode diskusi kelompok merupakan forum untuk bertukar informasi, pendapat dan pengalaman dengan tujuan mendapat pengertian yang lebih luas dan kejelasan permasalahan. Diskusi kelompok merupakan saluran yang paling baik untuk menjaga kredibilitas pesan dan menyediakan informasi.

Peningkatan pengetahuan juga dipengaruhi oleh tingkat pendidikan responden. Pada kelompok eksperimen mayoritas responden dengan tingkat pendidikan tinggi (SMA dan Diploma/Sarjana) yaitu $17 \mathrm{ibu}$ hamil $(45,4 \%)$ dan 18 orang suami $(69,2 \%)$. Penerimaan informasi tentang hubungan seksual masa kehamilan dapat lebih baik pada tingkat pendidikan yang tinggi. Pasangan dapat memperluas informasi tentang hubungan seksual masa kehamilan. Sejalan dengan penelitian Kusbiantoro (2014), bahwa pengetahuan orang tua dengan pendidikan menengah ke atas lebih baik dibandingkan pengetahuan orang tua dengan pendidikan menengah ke bawah dan pendidikan rendah.

Faktor pendukung lain diantaranya ka- 
rena pengambilan data post test dilakukan dengan jeda waktu satu minggu setelah pemberian pendidikan seksual pada domain pengetahuan. Proses adopsi inovasi merupakan proses kejiwaan/mental yang terjadi pada diri seseorang pada saat menghadapi suatu inovasi. Adopsi terjadi proses penerapan suatu ide baru sejak diketahui atau didengar sampai diterapkan ide baru tersebut. Proses perubahan perilaku ditentukan oleh jarak waktu. Cepat lambatnya proses adopsi tergantung dari sifat dinamika individu

Pada kelompok kontrol, hasil paired samples t-test menunjukkan tidak ada perbedaan yang bermakna domain pengetahuan antara hasil pre test dan post test, nilai $\mathrm{p}>\boldsymbol{\alpha}=0,05$. Hal ini karena tidak banyak peserta yang mendapatkan informasi dari sumber lain. Peserta dapat mengakses sumber informasi lain, namun tidak cukup membuat tertarik. Hovland \& Weiss (1951) dalam Ramdhani (2008), menyebutkan informasi yang disampaikan oleh seorang ahli secara langsung, maka pesan yang disampaikan akan lebih menarik dan mudah diterima.

Hasil uji independent samples t-test menunjukkan perbedaan yang bermakna pengetahuan kelompok intervensi dan kelompok kontrol, nilai $\mathrm{p}<\alpha=0,05$. Setelah diberikan pendidikan seksual pengetahuan kelompok intervensi lebih baik daripada kelompok kontrol. Sesuai dengan yang penelitian Kumboyono, (2004) untuk mendapatkan pengetahuan dalam proses belajar diperlukan media sebagai alat bantu. Media yang benar-benar dipahami akan mendorong peserta didik mendapatkan pengetahuan, sikap, dan praktek yang sesuai. Media penelitian ini yaitu booklet, berupa gambar dan pesan dengan tujuan memberikan informasi yang lebih spesifik dan menarik minat sasaran serta mempermudah penyampaian bahasa.

Pada domain sikap, menunjukkan perubahan sikap yang bermakna pada kelompok intervensi, nilai $\mathrm{p}<\alpha=0,05$. Sikap terbentuk melalui proses belajar dengan cara mengamati orang lain, hubungan terkondisi, pengalaman langsung dan mengamati perilaku diri sendiri. Penelitian ini juga sejalan dengan hasil penelitian Najimi, (2013) yang menyatakan pene rapan metode pendidikan pada ibu memiliki peran penting dalam merubah sikap ibu untuk pencegahan kejang demam pada anak-anak.
Metode diskusi pada kelompok yang sama membuat peserta dapat lebih terbuka mendiskusikan tentang pengalaman seksualnya. Responden mendapat kesempatan yang lebih baik untuk bertukar informasi, menyampaikan pendapat, pengetahuan maupun pengalaman seksualnya (Massey, 2006). Sejalan dengan penelitian Kumboyono, (2004) bahwa metode diskusi kelompok lebih efektif dalam merubah sikap remaja dalam perilaku penyim pangan seksual, dengan $\mathrm{p}<\alpha=0,05$. Melalui diskusi kelompok, remaja dapat lebih aktif berpartisipasi dalam diskusi, pertukaran informasi dan pengalaman dan dengan alat bantu booklet dapat lebih menarik minat remaja.

Hasil penelitian pada kelompok kontrol, tidak terdapat perbedaan yang bermakna pada domain sikap pre test dan post test, nilai $p>\alpha=0,05$. Hasil ini membuktikan bahwa tidak adanya paparan pendidikan kesehatan tidak menimbulkan perubahan hasil. Proses belajar tidak difasilitasi, pengalaman baru tidak didapatkan sehingga perubahan sikap tidak terjadi. Kelompok kontrol ini juga tidak melakukan diskusi dan tukar pengalaman dengan pasangan ibu hamil yang lain, dimungkinkan karena menganggap tabu dan malu membicarakan masalah seksual.

Penelitian ini menghasilkan peningkatan domain sikap kelompok intervensi lebih baik dibanding kelompok kontrol. Hasil uji paired samples $t$-test menunjukkan nilai $\mathrm{p}<\alpha=0,05$. Hasil ini sejalan dengan penelitian Musfiroh, (2014) bahwa terdapat pengaruh penyu-luhan terhadap sikap Ibu dalam memberikan toilet training pada anak usia balita dengan nilai $\mathrm{p}=0,001 \quad(<0,05)$. Pengetahuan yang tinggi mempengaruhi sikap dan perubahan perilaku. Dalam membentuk sikap yang utuh terdapat tiga komponen pokok, diantaranya adalah kepercayaan/ keyakinan, kehidupan emosional, dan kecenderungan untuk melakukan tindakan (Hikmawati, 2011 dalam Musfiroh, 2014). Untuk mewujudkan sikap menjadi suatu perbuatan nyata diperlukan faktor pendukung dan faktor pendorong. Pengetahuan yang benar dan baik dapat menyiapkan dalam praktik deng an baik.

Pada domain praktek, pendidikan seksual masa kehamilan terbukti secara signifikan meningkatkan praktek pemenuhan kebutuhan 
seksual pasangan masa kehamilan di Puskesmas Kasihan II Bantul, nilai $p<\alpha=0,05$. Pada penelitian ini telah menghasilkan pengetahuan dan sikap lebih baik setelah pendidikan seksual yang menimbulkan kecenderungan praktek lebih baik. Setiawati (2008) mengatakan bahwa praktek merupakan hubungan antara stimulus dan respon pada diri seseorang. Praktek yang diperoleh dari hasil pembelajaran akan bertahan lebih lama. Pengetahuan akan pentingnya sesuatu dan bagaimana cara melakukan, menjadi motivasi dasar bagi seseorang untuk menampilkan praktek. Semakin kuat pengetahuan seseorang akan kepentingan suatu tindakan, maka semakin kuat tindakan akan dilakukan. Faktor yang mendukung diantaranya adalah usia kehamilan. Responden kelompok intervensi mayoritas pasangan dengan ibu hamil trimester pertama, yaitu 21 responden $(80,8 \%)$. Pada saat pengambilan data post test usia kehamilan responden telah memasuki trimester kedua. Uwapusitanon (2004), Araujo, (2009) dan Senkumwong (2006), menyatakan keinginan berhubungan seksual ibu hamil meningkat pada trimester kedua, karena mual, muntah, pusing dan ketegangan pada payudara telah mulai hilang dan ibu hamil telah dapat beradaptasi. Perut yang mulai membesar tetapi masih dapat ditoleransi sehingga masih dirasakan nyaman dalam beraktivitas seksual. Menurut Brtnicka, (2009) peningkatan gairah seksual karena meningkatnya sirkulasi darah selama kehamilan dan mengalir langsung pada pelvis, peningkatan laju darah tersebut dapat meningkatkan orgasme yang berulang.

Pada kelompok kontrol, tidak ada perbedaan bermakna domain praktek antara pre test dan post test, nilai $\mathrm{p}>\alpha=0,05$. Pada kelompok kontrol ini tidak ada interaksi dengan petugas kesehatan secara langsung. Secara logis interaksi dengan petugas kesehatan akan mempengaruhi pengetahuan responden, yang akan mempengaruhi sikap dan praktek yang lebih baik. Pengetahuan adalah domain yang sangat penting dalam terbentuknya tindakan seseorang. Praktek akan bersifat langgeng apabila didasari pengetahuan yang positif.

Pada analisis independent samples $t$ test domain praktek menunjukkan hasil yang signifikan dengan $\mathrm{p}<\alpha=0,05$, artinya peningkatan domain praktek kelompok intervensi lebih baik dibanding kelompok kontrol. Hasil ini sejalan dengan penelitian Najimi, (2013) bahwa efisiensi intervensi pendidikan dalam meningkatkan pengetahuan, sikap dan praktek pencegahan kejang demam pada anak. Praktek pencegahan kejang demam dengan nilai $\mathrm{p}=0,01$, menunjukkan peningkatan praktek lebih baik dari kelompok kontrol. Penelitian ini juga mendukung penelitian Mohammadzadeh, (2012) yang bertujuan membandingkan pengetahuan, sikap dan praktek kesehatan pubertas pada kelompok yang belajar mandiri melalui pamflet dan kelompok yang melakukan diskusi kelompok. Hasil penelitian menunjukkan bahwa metode diskusi kelompok lebih efektif mempengaruhi perubahan penge-tahuan, sikap dan praktek kesehatan pubertas dibandingkan dengan metode belajar mandiri.

Secara umum penelitian ini membuktikan adanya pengaruh pendidikan seksualitas terhadap perilaku pemenuhan kebutuhan seksual pasangan masa kehamilan di Puskesmas Kasihan II Bantul.

\section{Penutup}

Perilaku (pengetahuan, sikap dan praktek) pemenuhan kebutuhan seksual pasa-ngan dengan ibu hamil di Puskesmas Kasihan II Bantul, setelah diberikan pendidikan seksual secara signifikan lebih baik daripada sebelum diberikan pendidikan seksual. Perubahan ini tidak terjadi pada kelompok kontrol, sehingga perilaku (pengetahuan, sikap dan praktek) pemenuhan kebutuhan seksual kelompok intervensi secara signifikan lebih baik dibandingkan kelompok kontrol.

\section{Daftar Pustaka}

Araujo, N.M., et al. 2012. Body and Sexuality During Pregnancy. Rev Esc Enferm USP, 46(3): 552-8.

Brtnicka, H., Weiss, P., \& Zverina, J. 2009. Human Sexuality during Pregnancy and The Postpartum Period. Bratsl Lek Listy, 110 (7): 427-431.

Frith, H. 2004. Focusing on Sex: Using Focus Groups in Sex Research. Sexualities: Sage publications, vol. 3(3): 275-297.

Kusbiantoro, D. 2014. Praktik Pencegahan Cedera Pada anak Usia Toddler Ditinjau Dari Peng- 
etahuan dan Sikap Orangtua tentang Bahaya Cedera di Desa Kembangbahu Kecamatan Kembangbahu Kabupaten Lamongan. Surya, 02 (18).

Kumboyono, H. M. \& Lestari, E. P. 2004. Perbedaan Pengaruh Pendidikan Seks Metode Simulasi dan Diskusi kelompok terhadap sikap remaja pada Perilaku Pencegahan Seks Menyimpang. Jurnal Kedokteran Brawijaya, 20 (1).

Massey, Z., Rising, S.S. \& Ickovics, J. 2006. Centering Pregnancy Group Prenatal Care: Promoting Relationship- Centered Care. Jognin, 35 (2).

Musfiroh, M., Beny, L. W. 2014. Penyuluhan Terhadap Sikap Ibu Dalam Memberikan Toilet Training Pada Anak. Jurnal Kemas, 9(2): 157-166.

Mohammmadzadeh, Z., et al. 2012. Puberty Health
Education in Iranian Teenagers: Self Learning or Lecture and Group Discussion. Iranian Journal of Medical Education

Najimi, A., et al. 2013. The Efect of Educational Program on Knowledge, Attitude and Practice of Mothers Regarding Prevention of Febrile Seizure in Children. Journal of Education Health Promotion, 2 (26).

Ramdhani, N. 2008. Pembentukan dan Perubahan Sikap. Yogyakarta : Fakultas Psikologi UGM.

Senkumwong, N., et al. 2006. The changes of sexuality in thai women during pregnancy. $J$ Med Assoc Thai, 89 (4), 124-129.

Uwapusitanon, W., \& Choobun, T. 2004. Sexuality and Sexual Activity in Pregnancy. $J$ Med Assoc Thai, 87(3), 45-4. 